\title{
La calidad de la educación universitaria, y su relación con la formación ciudadana ${ }^{1}$
}

\section{The quality of university education and his relationship to the civic education}

Alfonso Henríquez R. ${ }^{2}$

Resumen: El objetivo del artículo consiste en establecer la relación entre educación universitaria y formación ciudadana. Se propondrá en la presentación, que ambos elementos son inseparables, pues la primera, no puede simplemente ser reducida a un aspecto técnico, imprescindible sin duda, sino que deberá también abarcar una dimensión que capacite al sujeto para ser un partícipe inteligente en los debates que interesan a toda la sociedad.

Palabras clave: Calidad de la educación, educación superior, educación cívica.

Abstract: The aim of the paper is to establish the relationship between higher education and civic education. It will be proposed that both elements are inseparable, as the first one cannot simply be reduced to a technical issue. This is certainly essential, but it should also include a dimension that enables to the subject to be an intelligent participant in debates which concern the whole society.

Keywords: Quality at education, Civic education, Higher education

\section{Introducción}

En la primera parte de este artículo, abordaremos los distintos sentidos de lo público en relación a la universidad. Estas distinciones nos permitirán comprender la amplitud y vaguedad y del término, y circunscribir nuestro trabajo solo a uno de ellos. En la segunda sección, nos centraremos en estudiar la importancia que la educación tiene para el desarrollo de la autonomía del sujeto, y para el fortalecimiento de su rol como ciudadano. Y en la tercera sección, propondremos algunas vías para introducir la educación ciudadana en la universidad.

\section{La universidad y las dimensiones de lo público}

No es un tema pacífico determinar cuál es la relación entre lo público y la universidad, problemática que además se encuentra cruzada por el hecho que los actores

\footnotetext{
${ }^{1}$ Investigación financiada por la Vicerrectoría de Investigación de la Universidad de Concepción (VRID) en el marco del proyecto $\mathrm{N}^{\circ} 212.161 .007-1.0$ "Los conocimientos y actitudes respecto a la democracia y la ciudadanía que poseen los estudiantes que ingresan a la Universidad de Concepción" del que el autor es coinvestigador.

${ }^{2}$ Abogado, Licenciado en Ciencias Jurídicas y Sociales, Universidad de Concepción. Magíster en Filosofía Moral, Universidad de Concepción. Profesor instructor, Departamento de Historia y Filosofía del Derecho, Facultad de Ciencias Jurídicas y Sociales, Universidad de Concepción.
} 
en el debate parecen, precisamente, buscar en esta relación una especie de legitimidad social para sus instituciones. Así, en ocasiones la discusión aparenta centrarse en determinar qué tan pública es una universidad, como si en ello hubiese algo por sí mismo importante. Lo que nos interesa en primer lugar es esbozar algunos sentidos de la expresión 'público', a fin de reflexionar sobre cual o cuales de estos sentidos estarían más relacionados no con lo que 'sería' la universidad, sino que con el tipo de institución que necesitaríamos hoy. Al menos podemos identificar, si se sigue lo anterior, cinco sentidos de la expresión 'público':

I. El primero se vincula al concepto económico de 'bien público', es decir, aquella clase de bienes que producen beneficios para todos, hayan contribuido a su producción o no ${ }^{3}$. En este sentido, el conocimiento científico, tecnológico, artístico, intelectual, entre otros, que son clases de este tipo de bienes, y al ser generados por la universidad, volverán irrelevante la pregunta por el carácter privado o público de la misma. Lo anterior desde el punto de vista de quién es el dueño, pues lo central estaría en que serán de carácter públicas en tanto produzcan bienes de esa categoría.

II. Un segundo sentido lo encontramos en Habermas cuando asocia lo público con la esfera pública ${ }^{4}$. Así, señala que:

La 'publicidad' propiamente dicha hay que cargarla en el haber del ámbito privado, puesto que se trata de una publicidad de personas privadas. En el seno del ámbito reservado a las personas privadas distinguimos, por consiguiente, entre esfera privada y publicidad. La esfera privada comprende a la sociedad burguesa en sentido estricto, esto es, al ámbito del tráfico mercantil y del trabajo social; la familia, con su esfera íntima, discurre también por sus cauces. La publicidad política resulta de la publicidad literaria; media, a través de la opinión pública, entre el Estado y las necesidades de la sociedad ${ }^{5}$.

Lo público habría surgido como ese espacio intermedio entre lo estatal y lo propiamente privado, una zona en la cual se discuten y se enjuician los problemas generales y las decisiones del Estado ${ }^{6}$.

Desde esta perspectiva, la Universidad sería pública en tanto contribuye a la formación de una opinión pública informada sobre los temas que interesan a todos. Tal como indican Peña y Brunner, es probable que la esfera pública chilena deba tanto a los intelectuales de universidades estatales como (Universidad de Chile) como a universidades privadas (Pontificia Universidad Católica de Chile, Universidad de Concepción, Pontificia Universidad Católica de Valparaíso) ${ }^{7}$.

\footnotetext{
${ }^{3}$ KIESLING, Herbert J. "Pedagogical Uses of the Public Goods Concept in Economics". En The Journal of Economic Education. Volumen 21, No. 2, Spring, Published by: Taylor \& Francis, Ltd. 1990. p. 140.

${ }^{4}$ HABERMAS, Jurgen, "Historia y crítica de la opinión pública: La transformación estructural de la vida pública”, trad. Gustavo Gili. Barcelona, 2004. Editorial GG, $1^{\text {a }}$ edición.

${ }^{5}$ HABERMAS, Jurgen, Ibíd., p. 68

${ }^{6}$ BOLADERAS, Margarita. “La opinión pública en Habermas”. En: Análisis, N 26, 2001, p. 59.

7 BRUNNER, José Joaquín, PEÑA, Carlos. "La dialéctica publico privado entre el medioevo y la globalización”. En: BRUNNER, José Joaquín, PEÑA, Carlos (ed.). El conflicto de las universidades: entre lo público y lo privado. Santiago: Ediciones Universidad Diego Portales, 2011. p. 54
} 
III. Una tercera forma de entender la expresión 'público' es aquella en donde se asocia lo público con lo Estatal. Es la forma tradicional. En esta, la pregunta pasa por determinar quién es dueño del establecimiento educacional, con lo que la educación será pública cuando es provista por agencias estatales ${ }^{8}$, y privada en caso contrario. Como vemos, aquí la problemática sobre la naturaleza de los bienes que produce o de las funciones que cumple la Universidad, es irrelevante.

IV. Un cuarto sentido, asocia educación pública con la idea de un derecho a la educación. Según ha sostenido Fernando Atria, aunque circunscribiéndolo en lo esencial al problema de la educación primaria y secundaria, solo podemos hablar de educación pública, si a ella se accede sin restricciones que encuentren su origen en la capacidad de pago de las familias o en el proyecto educativo del establecimiento, pues

Cuando el que paga por la educación es el Estado, y no el individuo, ella deja de quedar condicionada a la capacidad del individuo de pagar por su educación. Éste sería el criterio relevante para definir lo que cuenta como educación pública. No tiene sentido entender que lo decisivo es el origen mismo del dinero, como si éste, cuando proviene del Estado, fuera en algún sentido diferente al que proviene de un individuo. Es una cuestión de acceso: educación pública=educación abierta a todos ${ }^{9}$.

Entonces el problema pasa por las condiciones de acceso. Aunque claro, en Chile el sistema se ha diseñado de tal forma que lo público coincide con lo Estatal, pero esta relación no sería necesaria ${ }^{10}$.

V. Un quinto sentido del término alude a la tarea emancipadora que la educación tiene, en el proyecto político democrático ${ }^{11}$. Aquí lo importante es la función que cumple la universidad, como mecanismo que permita romper el círculo vicioso de reproducción de las elites, de las desigualdades sociales y de los prejuicios, y con ello en contribución a homogenizar la cultura y a fortalecer la democracia ${ }^{12}$. La universidad pública sería desde esta perspectiva, aquella institución que entiende a sus alumnos como ciudadanos, y por tanto, como sujetos que necesitan desarrollar un pensamiento crítico y razonado que los habilite para enfrentarse a las discusiones sobre temas públicos con objetividad, siendo capaces de someter a cuestionamiento la tradición o el medio social en el cual están insertos. La universidad sería privada, cuando exprese más bien intereses y formas de vida de grupos particulares, no siendo lo primario la consideración del alumno como ciudadano.

Ahora bien, a efectos de nuestro trabajo, nos interesa detenernos en el último de estos sentidos. En efecto, la excelencia en la enseñanza universitaria se enlaza con la

\footnotetext{
8 ATRIA, Fernando. “QQué es educación pública?”. En: BELLEI, Cristián, CONTRERAS, Daniel, VALENZUELA, Juan Pablo (ed.). Ecos de la revolución pingüina. Santiago: UNICEF 2010. p. 156.

9 ATRIA, F. Ibíd., p. 164

${ }^{10}$ ATRIA, F. Ibíd., p. 174-175

11 PEÑA, C., BRUNNER, J.J, Ibíd., p. 54

12 PEÑA, C., BRUNNER, J.J, Ibíd., p. 55
} 
idea que este tipo de institución no debe solo formar profesionales, sino que también conseguir que estos puedan desarrollar habilidades y actitudes ciudadanas. Lo anterior, se debe a que en su actividad profesional, el sujeto deberá necesariamente relacionarse y encontrarse con otros, cuyo reconocimiento como seres dotados de igual dignidad, informará parte de lo que implicará ser un buen ciudadano. Así, dicho concepto supone un enfoque utilitarista, en donde la dimensión intersubjetiva no queda eclipsada por la dimensión 'habilidades técnicas'. A continuación se pretenderá reflexionar sobre estas consideraciones.

\section{¿Cuál es el rol de la educación en términos ciudadanos?}

La educación cumple con una finalidad ciudadana esencial pues, en base al principio de igualdad, entrega los mismos conocimientos a todos sin trabas para que pueden desempeñar de manera adecuada sus roles en cuanto ciudadanos. Esta finalidad es propia del mundo moderno que se ve enfrentado a grandes desafíos: la diversidad en sus variadas manifestaciones (cultural, sexual, étnica, etc.), la globalización, los Derechos Humanos, las problemáticas género, los desafíos del medio ambiente, la inmigración, entre otros asuntos. Todos ellos demandan del ciudadano un determinado juicio reflexivo que le permita afrontar adecuadamente dichas diferencias culturales, morales y políticas. Por lo que el egresado desde la educación superior, tal como indica Nussbaum, "tiene que ser el tipo de ciudadano capaz de actuar como participante inteligente en los debates que involucran esas diferencias" 13 , sea como profesional, elector, amigo, o parte de la opinión pública en general. Esta idea supone que existe un vínculo cercano entre democracia y educación, que va en el sentido de entender a la democracia como una institución dinámica, la cual necesita de ciudadanos activos que la representen ${ }^{14}$. La ciudadanía activa, por tanto, pretende expandir la noción de democracia, desde aquel mínimo, pero esencial acto democrático que es el voto, hacia una relación más profunda del ciudadano con lo político, generando una verdadera práctica democrática. Aquí es donde interviene la educación, pensada como el fundamento de un sistema democrático, y por tanto, comprometida con una praxis democrática.

En suma, si entendemos al educando, en primer lugar, como ciudadano, dicha consideración tan simple, generará que la educación universitaria no puede sustraerse a las demandas que la comunidad política formule en términos de ciudadanía, pues una democracia necesita un ciudadano capaz de pensar de forma racional y por sí mismo, sobre los problemas que aquejan a su comunidad. En Kant encontramos brillantemente plasmado este ideal, cuando reflexiona sobre el imperativo que pesa sobre el hombre, de abandonar su minoría de edad, en el sentido de servirse bien y con seguridad del propio entendimiento, sin acudir a la conducción de otros. Como Foucault ha observado comentando este texto, Kant plantea el problema de la reflexión crítica, en términos de la relación que el sujeto tiene con su propio presente, de ahí que las preguntas sean

\footnotetext{
${ }^{13}$ NUSSBAUM, Martha. El cultivo de la humanidad: una defensa clásica de la reforma en la educación liberal. Barcelona: Paidós, 2005. Traduccion: Juana Pailaya, $1^{\text {a }}$ edición, p. 27.

${ }^{14}$ RIBA, Jordi. "Filosofía Política, República y educación del ciudadano". En Res publica, volumen 16, $n^{\circ} 1,2006$, p. 61.
} 
¿Cuál es mi actualidad ¿Cuál es el sentido de esta actualidad? y ¿Que produce el hecho de que yo hable de ella?"15.

Para pensar por sí mismo, deben darse las condiciones materiales que efectivamente permitan el desarrollo de una mentalidad crítica. Así, no basta con decir que la persona ha escogido libremente, en el sentido de sin coacción, pues debe haber tenido efectivamente la oportunidad de elegir ${ }^{16}$. Este es un aspecto extremadamente relevante, debido a que los seres humanos por lo general pensamos que podemos hacer lo que nuestro entorno nos dice que podemos, aspecto que la doctrina conoce bajo la expresión: 'preferencias adaptativas' ${ }^{17}$ es decir, aquellas surgidas y justificadas por la tradición, el prejuicio, la discriminación o las carencias, y que subyacen a muchas de nuestras elecciones. Lo que debemos entender en este sentido, es que las opiniones que formulamos no son muy originales o independientes, pues expresan la voz de la tradición, los padres, los amigos o los convencionalismos sociales ${ }^{18}$. Este punto es clave para la discusión política, pues existe un estrecho nexo entre creencias y sentimientos que incide directamente en el debate público. Un sentimiento no es solo un impulso biológico, tiene en su base un determinado tipo de pensamiento o supuesto cultural o social. Así, si alguien se molesta o siente ira con una pareja homosexual que pasea en público tomados de la mano, gran parte del problema involucrado pasa por entender que tal comportamiento es una falta grave, de este modo el punto no es solo como manejar una emoción, sino que la idea que subyace a dicha emoción. Por ello, si una persona "llega a creer que el supuesto cultural es realmente inocente, o que la llamada falta fue en verdad una acción involuntaria, se puede esperar que ceda su enojo. La ira también cederá si la persona cambia su apreciación sobre la importancia de la falta cometida, considerándola una cuestión trivial"19. El asunto, por tanto, consiste en adquirir una cierta conciencia sobre el peso que la cultura tiene en el moldeamiento de nuestras percepciones. Nussbaum ha distinguido al menos cinco áreas en que este proceso operan $^{20}$ : la sociedad enseña qué emociones hacer públicas y cómo manejarlas; instruye sobre cómo categorizarlas (algunas culturas valoran positivamente la ira, mientras que otra no); cómo evaluarlas dentro de cada categoría; cómo concebir a las categorías emocionales en general; y, en último lugar, la posición de los individuos dentro de las categorías. Es decir, mucho de lo que creemos en realidad no es nuestro, lo hemos recibido en herencia, lo que se vuelve problemático cuando no somos capaces de reflexionar críticamente sobre ello.

Amartya Sen ha desarrollado bien este tipo problemas. Se puede pensar, indica, en la siguiente afirmación: "el sol y la luna parecen similares en tamaño"24. Desde un

\footnotetext{
${ }^{15}$ FOUCAULT, Michel. El gobierno de sí, y de los otros. Buenos Aires: Fondo de Cultura Económica. Traducción de: Horacio Pons, $1^{\text {a }}$ edición, 2009. 429. p. 31.

${ }^{16}$ SEN, Amartya, Development as Freedom. New York: Oxford University Press, 2001. $2^{\text {a }}$ edición. p. 30.

17 NUSSBAUM, Martha. Women and human development: the capabilities approach. New York: Cambridge University Press, 2001. $1^{\text {a }}$ edición, p. 120.

18 NUSSBAUM, Martha, El cultivo de la humanidad: una defensa clásica de la reforma en la educación liberal, 2005, p. 51.

${ }^{19}$ NUSSBAUM, Martha, Ibíd., p. 51

${ }^{20}$ NUSSBAUM, Martha, Ibíd., pp.241-244

${ }^{21}$ SEN, Amartya. La idea de justicia. Madrid: Taurus, 2009. $1^{\text {a }}$ edición, traducción Hernando Valencia Villa, p. 186.
} 
cierto punto de vista, es una creencia que no descansa solamente en la mente del observador, pues puede ser compartida por otros que están en su misma posición, de ahí que a este fenómeno lo denomine como 'objetividad posicional' ${ }^{25}$. Éste concepto se relaciona con aquellos que puede ser mirado desde una cierta posición, de ahí que lo observado sea invariante con respecto a la persona, pero relativa en cuanto a la posición ${ }^{26}$, es decir, cualquier en esa posición de observador vería lo mismo. El problema se aprecia, para lo que nos interesa, cuando llevamos la 'objetividad posicional' a temas que tienen que ver con la ética, o con decisiones políticas que pueden afectar a todos, pues "el dominio de las perspectivas posicionales puede hacer que para la gente resulte muy difícil trascender sus visiones posicionalmente limitadas"27.

Esto es particularmente complejo ya que, tal como hemos dicho, las democracias modernas suponen una gran diversidad de problemas, pero a la vez, una gran diversidad de perspectivas sobre cómo afrontarlas y solucionarlas. Sen entrega un ejemplo muy claro. En culturas que tradicionalmente han subordinado a la mujer, la norma cultural es tan fuerte que se requiere una gran independencia mental para pensar a las mujeres de un modo diferente ${ }^{28}$, de hecho, podría darse el caso que tal inequidad no se presente como un problema de discriminación, pues ya las propias mujeres lo han adoptado en tanto una práctica normal y deseable, han generado una preferencia adaptativa. De estas mujeres, sin embargo, no podemos decir que han estado en condiciones de 'elegir' sus vidas.

Tomar conciencia de estos aspectos es central para el razonamiento público, sobre todo cuando la objetividad posicional nos lleva a conclusiones erróneas sobre la realidad, distorsionando el entendimiento social y la evaluación de los asuntos públicos $^{29}$. En este sentido, el espacio que la educación abre, permitiría promover una libertad racional, por medio de una educación liberal. Liberal, tiene en los clásicos dos sentidos que nos permitirán comprender nuestro actual dilema. Séneca, en sus cartas a Lucilio, entiende que una educación solo puede ser liberal, cuando sea capaz de hacer pensar a los alumnos por sí mismos y someter a un examen crítico las costumbres sociales, lo que la diferencia de los tradicionales studia liberalia, en los que los alumnos aprenden los valores y costumbres de las clases dirigentes. Se contraponen por tanto, dos formas de entender el proceso educativo, en la primera el acento está en la formación de un sujeto autónomo que sea capaz de reflexionar con independencia de la tradición sobre su entorno, en la segunda, el énfasis está precisamente en la mantención de la tradición.

Como ha reflexionado Walzer, históricamente las escuelas han sido instituciones de elite dominadas por el nacimiento, la sangre, la riqueza o el sexo $^{27}$, elementos que

${ }^{22}$ NUSSBAUM, Martha, Ibíd., p. 187

${ }^{23}$ NUSSBAUM, Martha, Ibid., p. 188

${ }^{24}$ NUSSBAUM, Martha, Ibíd., p. 192

${ }^{25}$ NUSSBAUM, Martha, Ibid.

${ }^{26}$ NUSSBAUM, Martha, Ibíd., p. 198

${ }^{27}$ WALZER, Michael, Las esferas de la justicia, Fondo de Cultura Económica, México D.F., 2011. $2^{\mathrm{a}}$ edición, traducción: Heriberto Rubio, p. 211. 
han determinado las finalidades de la institución y quienes pueden acceder a ella. Así, se han favorecido intereses de clase con el fin de asegurar a los padres que sus hijos solo se relacionen con sus iguales ${ }^{30}$, lo que crea una sociedad en que las escuelas sean, más bien, como sus casas de origen ${ }^{31}$. Así, esto va perpetuando las jerarquías sociales y los espacios de exclusión.

Por qué esto es problemático? Debido a que conceptos como los de segregación social, fragmentación social o diferenciación estructural pretenden dar cuenta que, cuando los grupos sociales pierden contacto, se aíslan, y caen en la violencia y la desorganización $^{32}$. En definitiva, asistimos a la construcción de una frontera moral, en que el otro ya no es reconocido como un igual, pues la posibilidad de someter las propias creencias a un examen crítico en un espacio plural, se hará muy difícil. El proceso opera por medio del diseño de esferas distantes, las cuales ya no se pueden medir en términos de grado, sino que:

Se distinguen por pertenencias a mundos culturales que difieren entre sí en virtud de los valores, las expectativas y los modos de vida que los organizan"1. Al final del proceso tenemos "la creación de una sociedad donde no existiría ninguna base geográfica sólida, ni una lealtad basada en las costumbres, sino más bien una considerable variedad de grupos ideológicos (..) Los ciudadanos serían altamente móviles, desarraigados, y transitarían con facilidad de una asociación a otra. Sus movimientos equivaldrían a sus elecciones, de modo que evitarían las interminables discusiones y concesiones de la actividad política democrática, cuyos participantes están más o menos permanentemente compenetrados entre sí ${ }^{30}$.

Es por esta razón, que la educación pública, tanto en el sentido de una educación a la que se pueda acceder sin tomar en cuenta el origen o la capacidad de pago del alumno (como en el que nos interesa para este trabajo), de una educación que permita formar ciudadanos, es un espacio que media entre la familia y el Estado. Lo que se busca con la educación pública es que los alumnos no se conviertan en meros objetos de sus familias y de las jerarquías en las que están inmersas ${ }^{31}$, pero tampoco que pasen del control de las familias al control del Estado, lo que supondría intercambiar una jerarquía por otra. El sentido, de forma particular en la universidad, es que los alumnos aprendan a ser ciudadanos, en tanto se deficiente un estándar de reflexión crítica y amplia que les permita mirar sus lugares de origen, como realidades insertas en una sociedad plural, en la que también existen otros mundos que han de reconocer como igualmente dignos de respeto y consideración. Lograr lo anterior implica transitar desde la tradición a la reflexión racional sobre la misma, que exige incorporar un aspecto central en el proceso de toma de decisiones: la perspectiva del otro, esto es lo que Sen denomina "comportamiento razonable en relación a otras personas" ${ }^{32}$. En una democracia, todas

\footnotetext{
28 WALZER, Michael, Ibíd. p.229.

29 TIRAMONTI, Guillermina, ZIEGLER, Sandra. La educación de las elites, Aspiraciones, estrategias, oportunidades, Buenos Aires: Paidós, Buenos Aires, 2008. 1ª edición, p. 28.

${ }^{30}$ WALZER M. Ibíd., p. 229

${ }^{31}$ WALZER M. Ibíd., p. 227

${ }^{32}$ SEN, Amartya. La idea de justicia. Madrid: Taurus, 2009. $1^{\text {a }}$ edición, traducción Hernando Valencia
} 
las personas cuentan por igual, lo que implica que todas entran en el espacio público, en dicha condición, y que por tanto, merecen un trato igual. No obstante, basta ver los debates públicos sobre temas como el matrimonio igualitario, la pobreza, la educación, o incluso, como se encuentran diseñadas nuestras ciudades para recibir a personas con discapacidades, para darse cuenta que los intereses de algunas personas, reciben mayor atención y protección que los de otras. Las razones de ello, descansan entre otras, en una falta de herramientas conceptuales que efectivamente permitan incorporar la perspectiva del otro. Ya Adam Smith había reflexionado sobre el hecho que debemos observar nuestros sentimientos desde cierta distancia, "con el propósito de escrutar no solo la influencia de los intereses creados, sino también el impacto de las costumbres y tradiciones arraigadas" 33 , las cuales como ya se ha dicho, muchas veces dificultan el juicio.

La idea que sostenemos, siguiendo la senda de Sen o Rawls, implica que las discusiones públicas deben realizarse con un cierto ethos democrático que permita arribar a soluciones imparciales, entendidas como aquellas que han minimizado la injerencia de los intereses personales o sectarios y que toman en cuenta para la resolución del problema, los intereses y preocupaciones de otros. Para ello, el ciudadano debe estar en condiciones de poder comunicar al resto sus creencias, de tal manera que puedan ser entendidas, y aceptar que dichas creencias, puedan participar en debates en que sean sometidas al escrutinio racional de terceros ${ }^{34}$.

Este procedimiento exige tomar en cuenta diferentes perspectivas, que van desde las que defienden los interesados, hasta las que podrían adoptar otros que no lo están directamente en la discusión, lo cual da lugar según Sen a distinguir entre una imparcialidad cerrada y otra abierta. Ambas están dirigidas a superar los prejuicios locales, pero la primera lo hace incorporando solo las visiones de aquellos para quienes la controversia es relevante, mientras que la segunda lo hace invocando a observadores que están fuera del grupo de interés, país o nación ${ }^{35}$. El punto que se quiere recalcar con esto, no es que para cada decisión se deba consultar a todos, sino algo diferente, lo importante pasa porque si se quiere tomar en serio la democracia, y con ello, el logro de decisiones realmente imparciales y objetivas que no se deban solo a intereses particulares, el escrutinio debe ser real, por lo que debe colocarse atención a los diferentes puntos de vista que reflejen otras experiencias que pudiesen ser relevantes ${ }^{36}$, lo que permitirá someter las propias visiones, a un escrutinio razonado. En definitiva, las elecciones que tomemos, y que nos puedan afectar a todos, deben basarse en un razonamiento riguroso, el cual exige más y mejor información, y no tomar la perspectiva de los otros, como inválida $a$ priori. 


\section{La educación ciudadana en la universidad}

Como lo hemos señalado, la universidad puede ayudar en esta área en tanto contribuye a la formación de un ciudadano activo, es decir, ejercitado en habilidades que le permitan enfrentar razonadamente los debates públicos. Lo anterior va transformando a esa universidad en pública, si trata a sus alumnos como ciudadanos y les entrega las herramientas necesarias para romper con el círculo de reproducción de las elites, lo que conduce a un fortalecimiento a la democracia. Para ello será preciso incorporar algunas perspectivas curriculares en los planes de estudio, que permitan a los estudiantes pensar por sí mismos; situarse en el lugar del otro y pensar de tal forma que exista una conexión entre el discurso y la $\operatorname{praxis}^{37}$. En relación a la primera, es preciso que el estudiante sea capaz de cuestionar sus propias creencias, sometiéndolas a un examen de racionalidad, coherencia y respeto por la dignidad, y que nos las acepte solo porque sean transmitidas por la tradición ${ }^{38}$. En lo que respeta a la segunda, esta encarna un aspecto clave pero escasamente incorporado en la educación, y que nosotros llamamos 'situarse en el lugar de otro', pero que Nussbaum conceptualiza mejor bajo la expresa 'imaginación narrativa'. Esta se refiere a la "capacidad de pensar como seria estar en el lugar de otra persona, ser un lector inteligente de la historia de esa persona, y comprender las emociones, deseos y anhelos que alguien así pudiere experimentar"39. Esta capacidad constituye un primer paso, y que se explica por el hecho que para juzgar adecuadamente los intereses de otra persona, es imprescindible verlos desde su perspectiva, poder empatizar con sus necesidades, y conocer el significado que estos tienen para el sujeto, a la luz del contexto en el cual se insertan. De otra forma, el alumno será como una caja cerrada, que solo atienda a su propio y local punto de vista. La tercera capacidad, apunta a una necesaria conexión entre estos aspectos y la práctica, es decir, de cómo realmente conseguir que en la vida real informen el actuar de personas concretas. Por tanto, estos no pueden pensarse como simples herramientas teóricas, sino que en sus disciplinas particulares, en el trabajo que realicen, que siempre es en relación a otro y a la comunidad y a sus necesidades, carencias o intereses, incorporen estas dimensiones, pues ese el objetivo último.

Una forma de hacerlo sería insertar temáticas relacionadas con Derechos Humanos, como cursos electivos o bien obligatorios según la realidad de cada disciplina, pero que sean ofrecidos de forma transversal para todas las carreras. En un estudio muy interesante financiado por el Instituto Nacional de Derechos Humanos (INDH) titulado "Diagnóstico sobre la incorporación de los derechos humanos en las carreras de derecho de Chile", y llevado a cabo por Claudio $\mathrm{Nash}^{40}$, se ha problematizado en que medida y que razones, harían relevante una enseñanza del derecho, con énfasis en Derechos Humanos. Según se lee en el informe, al año 2011, existían algunos problemas que conviene destacar:

\footnotetext{
${ }^{37}$ RUIZ SCHNEIDER, Carlos. Nota sobre la idea de un derecho a la educación: desde la filosofía política al Chile actual. En Anuario de Derechos Humanos, N 8, 2012, p. 198.

${ }^{38}$ NUSSBAUM, Martha. El cultivo de la humanidad: una defensa clásica de la reforma en la educación liberal. Barcelona: Paidós, 2005. Traducción: Juana Pailaya, $1^{\text {a }}$ edición, p. 28.

${ }^{39}$ NUSSBAUM, Martha, Ibíd. p. 30

${ }^{40}$ INSTITUTO NACIONAL DE DERECHOS HUMANOS. "Diagnóstico sobre la incorporación de los derechos humanos en las carreras de derecho de Chile”. Autor: Claudio Nash, 2011. [consulta 4-6-2012] Disponible en : www.cdh.uchile.cl/media/publicaciones/pdf/80.pdfn
} 
-La formación en derechos humanos se concreta de manera escasa e indirecta en las misiones de las universidades y sus perfiles de egreso.

-Existe un altísimo porcentaje de cátedras que no abordan las obligaciones internacionales del Estado y la recepción del Derecho Internacional en el Derecho interno, lo que representa precisamente uno de los mayores problemas para la protección de los derechos humanos "puesto que gran parte de los profesionales del Derecho aun no conciben los derechos humanos consagrados internacionalmente como directamente exigibles al Estado ni que formen parte integrante de nuestro ordenamiento jurídico" 41 .

-El porcentaje de Universidades que no incorporan instrumentos internacionales o jurisprudencia internacional, no llega al $50 \%$.

-Solo un $20 \%$ de las Universidades, aborda algunas temáticas relacionadas con grupos vulnerables.

Esta realidad revela que aun en el espacio más cercano a lo que podría ser la reflexión sobre Derechos Humanos, concretado en las Facultades de Derecho, el énfasis es menor. Dicho déficit podría ser superado por ejemplo, asumiendo cada Universidad un compromiso con la formación de profesionales que estén comprometidos con los derechos humanos en sus misiones o perfiles de egreso, instando por la existencia de cursos obligatorios, promoviendo el uso de normativas y jurisprudencia internacional, incentivando la visión que los derechos humanos son exigibles al Estado, alentando la preocupación por el estudio de grupos vulnerables o desprotegidos, entre otros.

Sin embargo, lo anterior no debiese estar restringido a las facultades de Derecho, pues como hemos defendido, es la universidad como institución la que debe incentivar la incorporación de estos temas para todas las carreras. De esta forma, la carrera de origen podría condicionar el énfasis en determinadas áreas, o bien un cierto abordaje metodológico o conceptual, pero esto no nos debería hacer perder de vista que el objetivo final, es la formación de habilidades críticas y reflexivas que le permitan a los universitarios, enfrentarse de una forma más racional a los desafíos contemporáneos. De lo que se trata es que, por medio de la formación en derechos humanos, se evite caer en la negligencia excluyente o en el parroquialismo procedimental:

1) Evitar la negligencia excluyente: los procesos de decisión pueden excluir la voz de personas que no forman parte del grupo focal, pero que se verán afectadas por dichas decisiones ${ }^{42}$. Un ejemplo son las personas con discapacidad. Estas personas, se vuelven en buena medida discapacitados, porque el entorno en el cual se desarrollan no es amigable con ellos, así los espacios públicos y privados no están diseñados para los que se desvían del estándar de normalidad ${ }^{43}$, esgrimiéndose muchas veces el argumento que los presupuestos son insuficientes, y que por ello, deben destinarse a satisfacer las necesidades de la mayoría.

\footnotetext{
${ }^{41}$ NUSSBAUM, Martha, Ibíd. p. 37.

42 SEN Amartya. Ibíd., p. 168

${ }^{43}$ NUSSBAUM, Martha. El cultivo de la humanidad: una defensa clásica de la reforma en la educación liberal. Barcelona: Paidós, 2005. Traduccion: Juana Pailaya, $1^{\text {a }}$ edición, p. 352.
} 
Aun así, nos parece que el problema no es tanto el financiamiento, creemos que la traba central pasa por el hecho que la sociedad desde el inicio está pensada para colocar atención en un cierto grupo, y en los intereses y necesidades de ese grupo, construyéndose el espacio público en función de los mismos. Pensemos por ejemplo, como en carreras como arquitectura u otras relacionadas, una enseñanza empática con las necesidades de otros, y que logre insertar con vigor en las mallas conocimientos sobre los derechos humanos de las personas discapacitadas o reflexiones sobre la igualdad o la discriminación, contribuiría a la formación de competencias profesionales mas acordes con algunas de los desafíos mas apremiantes hoy.

2) Evitar el parroquialismo procedimental: es posible que un determinado grupo arribe a soluciones que se encuentran distorsionadas por prejuicios o sesgos sociales o culturales, los cuales no son fáciles de detectar. Para ello, retirarse un poco, y adoptar la perspectiva de un observador imparcial podría contribuir a soluciones mas objetivas. Un buen ejemplo, de este parroquialismo, lo constituyó el caso de la jueza Atala. Sin duda, jueces bien intencionados, entendieron a priori que la orientación sexual de la madre, era razón suficiente para dirimir la controversia sobre el cuidado personal de sus hijas.

No obstante, como ha puntualizado el informe del INDH sobre la enseñanza de derechos humanos en las facultades de derecho, uno de los principales problemas que afectan a la comunidad jurídica, es precisamente este parroquialismo, graficado en las dificultades para entender incorporadas las obligaciones internacionales dentro de derecho interno, pero sobre todo, por la poca relevancia que se la da a otras experiencias jurídicas, plasmadas en la jurisprudencia comparada. Poder conocer otras experiencias que se han enfrentado a problemas similares, contribuye a sacar a la luz muchos prejuicios que existen sobre la homosexualidad y el lesbianismo, en este sentido la interesante evolución del Tribunal Europeo sobre Derecho Humanos, concretada en temas como la adopción de menores por parte de padres homosexuales, permite apreciar como la doctrina ha ido avanzando hacia consideraciones mas abiertas sobre la orientación sexual.

Esto que es válido para Derecho, podría serlo igualmente para cada carrera, pensando en la implementación de cursos interdisciplinarios sobre igualdad, compuestos por psicólogos, abogados, sociólogos, filósofos o médicos, que aporten desde sus áreas, una visión que permita acceder a esto que llamamos 'la comprensión del otro, en tanto que otro', es decir mirar los problemas desde una perspectiva mas informada, pero también mas empática.

\section{A modo de conclusión}

Como vemos, no podemos disociar con tanta facilidad los conceptos de calidad, educación universitaria y ciudadanía, pues concebimos a los alumnos en primer lugar como ciudadanos. Dada esta calidad, el alumno-ciudadano de una democracia moderna, necesita cultivar los aspectos que hemos reseñados, pues esto permitiría precisamente fortalecer su rol como ciudadano. Esto es así, pues la democracia no se puede agotar en la dimensión institucional y en el derecho a sufragio como sus manifestaciones más relevantes. La democracia, como ha sido destacado por la reflexión política reciente, es 
esencialmente el gobierno por discusión ${ }^{44}$, de ahí que la deliberación pública emerja como el componente a fortalecer para conseguir una democracia mas profunda. Lo anterior permite comprender la importancia de un proceso de participación sobre los asuntos que nos interesan a todos, basado en la imparcialidad abierta, que permita el escrutinio crítico, abierto a los argumentos de otros y sensible a la información relevante que pueda surgir ${ }^{45}$. Una democracia así concebida, es un lugar más receptivo a la protección de las minorías, los marginalizados, las personas de escasos recursos, entre otros, impidiendo transformarla simplemente en lo que las mayorías digan. El escrutinio público, y la capacidad de participar en él dotado de adecuadas herramientas conceptuales y de razonamiento, permiten minimizar la presión que muchas veces las mayorías ejercen sobre las minorías, e incluso, minorías sectarias sobre los intereses de todos, al someter a un debate imparcial los argumentos de todos los involucrados.

Por tanto, lo "público" en educación, estará figurado por aquel tipo de educación embarcada en una comprensión amplia de la calidad, que le de espacio al razonamiento crítico y a las necesidades del otro, lo que supondrá avanzar hacia el quinto tipo sentido del término "público", reseñado al comienzo del trabajo. Dicha finalidad solo será posible, si entendemos al alumno como ciudadano, cuya ciudadanía no se agota en el voto, sino que precisa de un ejercicio activo y diario de la misma, encarnado en el respeto de la dignidad de todos y de los valores de una sociedad democrática y plural.

\section{Referencias bibliográficas}

ATRIA, Fernando. “Qué es educación pública?”. En: BELLEI, Cristián, CONTRERAS, Daniel, VALENZUELA, Juan Pablo (ed.). Ecos de la revolución pingüina. Santiago: UNICEF 2010. p. 153-182.

BOLADERAS, Margarita. "La opinión pública en Habermas". En: Análisis, $\mathrm{N}^{\circ} 26$, 2001, p. 59. p. 51-70.

BRUNNER, José Joaquín, PEÑA, Carlos. "La dialéctica publico privado entre el medioevo y la globalización”. En: BRUNNER, José Joaquín, PEÑA, Carlos (ed.). El conflicto de las universidades: entre lo público y lo privado. Santiago: Ediciones Universidad Diego Portales, 2011. 460 p.

FOUCAULT, Michel. El gobierno de sí, y de los otros. Buenos Aires: Fondo de Cultura Económica. Traducción de: Horacio Pons, $1^{a}$ edición, 2009. 429 p.

INSTITUTO NACIONAL DE DERECHOS HUMANOS. "Diagnóstico sobre la incorporación de los derechos humanos en las carreras de derecho de Chile". Autor: Claudio Nash, 2011. [consulta 4-6-2012] Disponible en : www.cdh.uchile.cl/media/publicaciones/pdf/80.pdf

\footnotetext{
${ }^{44}$ SEN A. Ibíd., p. 354

${ }^{45}$ SEN A. Ibíd., p. 391
} 
HABERMAS, Jurgen, "Historia y crítica de la opinión pública: La transformación estructural de la vida pública", trad. Gustavo Gili. Barcelona, 2004. Editorial GG, $1^{\text {a }}$ edición. 352 p.

KIESLING, Herbert J. "Pedagogical Uses of the Public Goods Concept in Economics". En The Journal of Economic Education. Volumen 21, No. 2, Spring, Published by: Taylor \& Francis, Ltd. 1990. p. 137-147.

NUSSBAUM, Martha. El cultivo de la humanidad: una defensa clásica de la reforma en la educación liberal. Barcelona: Paidós, 2005. Traduccion: Juana Pailaya, $1^{\text {a }}$ edición, $338 \mathrm{p}$.

NUSSBAUM, Martha. Women and human development: the capabilities approach. New York: Cambridge University Press, 2001. 1ª edición, 312 p.

NUSSBAUM, Martha. El ocultamiento de lo humano. Buenos Aires, Katz, 2006, $1^{\text {a }}$ edición, traducción: Gabriel Zadunaisky, 422 p.

RIBA, Jordi. "Filosofía Política, República y educación del ciudadano". En Res publica, volumen $16, \mathrm{n}^{\circ} 1,2006$, p. 61-76.

RUIZ SCHNEIDER, Carlos. Nota sobre la idea de un derecho a la educación: desde la filosofía política al Chile actual. En Anuario de Derechos Humanos, N 8, 2012, p. 195207.

TIRAMONTI, Guillermina, ZIEGLER, Sandra. La educación de las elites, Aspiraciones, estrategias, oportunidades, Buenos Aires: Paidós, Buenos Aires, 2008. $1^{\text {a }}$ edición, 202 p.

SEN, Amartya, Development as Freedom. New York: Oxford University Press, 2001. $2^{\mathrm{a}}$ edición. 366 p.

SEN, Amartya. La idea de justicia. Madrid: Taurus, 2009. $1^{\text {a }}$ edición, traducción Hernando Valencia Villa, 499 p.

WALZER, Michael, Las esferas de la justicia, Fondo de Cultura Económica, México D.F., 2011. $2^{\text {a }}$ edición, traducción: Heriberto Rubio, 333 p. 